\title{
Long-Term Effect of Gabapentin in Stiff Limb Syndrome: A Case Report
}

\author{
Trygve Holmøy \\ Department of Neurology, Ulleval University Hospital, Oslo, Norway
}

Dear Sir,

Diagnosis and treatment of stiff person syndrome (SPS) and stiff limb syndrome (SLS) are often challenging [1]. Diazepam is widely used as first-line symptomatic treatment, but high doses, leading to sedation, are often needed. Alternative symptomatic treatment is therefore needed, and several other GABAergic drugs have been suggested [2]. However, clinical trials are hampered by the rarity of the disease, and actual reports on the effect of these drugs are scarce or lacking. This is the first case report on gabapentin in SPS and SLS, suggesting that gabapentin may have good and enduring effects combined with a favourable adverse effect profile in these conditions.

\section{Case Report}

The patient is a 39 -year-old previously healthy female, who developed stiffness and painful muscle cramps in the legs at the age of 30 years. After 2 months she was not able to walk without aid and used a wheelchair. The stiffness was less pronounced in the right leg and did not affect the trunk, arms, neck or face. Emotional and physical stress, as well as exposure to heat or cold, triggered painful muscle cramps.
Neurological examination revealed increased muscle tone in the left leg but was otherwise normal. Thyrotropin was slightly elevated. Other routine blood analyses, cerebrospinal fluid examination and magnetic resonance imaging of the brain and spinal cord were normal. Electromyography showed continuous and simultaneous motor unit firing in agonistic and antagonistic muscles. A diagnosis of SLS/SPS was confirmed by elevated antibodies against the $65-\mathrm{kD}$ isoform of glutamic acid decarboxylase (GAD65) in serum (1,164 units, normal $<100)$, and presence of antiGAD65 antibodies in cerebrospinal fluid.

Both rigidity and spasms responded to treatment with $12 \mathrm{mg}$ diazepam daily. She became able to walk without aid, but pronounced sedation prohibited car driving. Gabapentin was therefore introduced at $400 \mathrm{mg} 3$ times daily after 2 months and was immediately followed by further symptom relief and allowed reduction of diazepam to 5-7 mg daily. The condition remained stable for another half year. Gabapentin was then increased to 2,400 mg per day over a period of 1 week, with further improvement of rigidity and spasms. The condition has remained stable on this treatment for 7 years. She has not recognized sedation or other overt side effects, and intravenous immunoglobulins have not been needed. The patient is able to go cross-country skiing and walk $5 \mathrm{~km}$ without aid, drive a car and work in an office. Fear for relapse makes her reluctant to alter the medication. She has developed hypothyroidism, but not diabetes mellitus.

\section{Discussion}

It has been suggested that intrathecal production of anti-GAD65 antibodies and reduced levels of GABA contribute to the symptoms in SPS [3]. Antibodies to $\mathrm{GABA}(\mathrm{A})$-receptor-associated protein could also impair GABAergic pathways through reduced expression of GABA(A) receptors [4]. Gabapentin interacts with GABA receptors and enhances GABAergic neurotransmission [5]. Although the effect of gabapentin in this patient may support the involvement of GABA in the pathogenesis of SPS and SLS, it must be remembered that the mechanism of gabapentin may involve pathways distinct from GABAergic neurotransmission.

SLS may be regarded as a focal subtype of SPS or as a distinct entity. In support of the latter, it has been reported that SLS is associated with poorer response to GABA-

\section{KARGER}

Fax +41613061234 E-Mail karger@karger.ch www.karger.com (c) 2007 S. Karger AG, Basel 0014-3022/07/0584-0251\$23.50/0

Accessible online at: www.karger.com/ene
Trygve Holmøy

Department of Neurology

Ulleval University Hospital

NO-0407 Oslo (Norway)

Tel. +47 2307 3809, Fax +47 2307 3510, E-Mail trygve.holmoy@medisin.uio.no 
ergic treatment and rarely with antiGAD65 antibodies or other signs of autoimmunity [6]. However, several reports describe antibodies to GAD65 in SLS [7]. The combination of leg symptoms, elevated anti-GAD antibodies and excellent response to GABAergic treatment indicates that this is a case of SLS related to SPS.

As in every case report, spontaneous remission cannot be totally excluded. However, close temporal relation between gabapentin treatment and symptom relief, and the usually chronic course of SPS and SLS, make a spontaneous remission unlikely [8]. Given the painful and disabling consequences of a relapse, discontinuation of the treatment in order to test this even- tuality is not justified. We conclude that gabapentin may be useful in SLS and SPS.

\section{References}

1 Wilson RK, Murinson BB: Sudden spasms following gradual lordosis - the stiff-person syndrome. Nat Clin Pract Neurol 2006;2: 455-459.

2 Vasconcelos OM, Dalakas MC: Stiff-person syndrome. Curr Treat Options Neurol 2003; 5:79-90.

3 Dalakas MC, Li M, Fujii M, Jacobowitz DM: Stiff person syndrome: quantification, specificity, and intrathecal synthesis of GAD65 antibodies. Neurology 2001;57:780-784.

4 Raju R, Rakocevic G, Chen Z, Hoehn G, Semino-Mora C, Shi W, et al: Autoimmunity to GABAA-receptor-associated protein in stiff-person syndrome. Brain 2006; 129: 3270-3276.

5 Czapinski P, Blaszczyk B, Czuczwar SJ: Mechanisms of action of antiepileptic drugs. Curr Top Med Chem 2005;5:3-14.

6 Barker RA, Revesz T, Thom M, Marsden CD, Brown P: Review of 23 patients affected by the stiff man syndrome: clinical subdivision into stiff trunk (man) syndrome, stiff limb syndrome, and progressive encephalomyelitis with rigidity. J Neurol Neurosurg Psychiatry 1998;65:633-640.

7 Bartsch T, Herzog J, Baron R, Deuschl G: The stiff limb syndrome - a new case and a literature review. J Neurol 2003;250:488-490.

8 Brown P, Rothwell JC, Marsden CD: The stiff leg syndrome. J Neurol Neurosurg Psychiatry 1997;62:31-37. 